\title{
Assessing foreign exchange risk associated to a public debt portfolio in Ghana using the value at risk technique
}

\author{
Alice Constance Mensah ${ }^{1}$, Ebenezer Okyere ${ }^{2}$, Osei Antwi ${ }^{1}$, Prince Kumi ${ }^{3}$, Joseph Dadzie ${ }^{1}$, \\ Martin Owusu Amoamah ${ }^{1}$
}

${ }^{1}$ Mathematics and Statistics Department, Accra Polytechnic, Accra, Ghana

${ }^{2}$ Research Department, Bank of Ghana, Accra, Ghana

${ }^{3}$ Accountancy Department, Accra Polytechnic, Accra, Ghana

\section{Email address:}

alicecabakah@yahoo.com (A. C. Mensah), ebenezer.okyere@bog.gov.gh (E. Okyere), kobenagyesi@yahoo.com (J. Dadzie), martin_amoamah@yahoo.com (M. O.Amoamah)

\section{To cite this article:}

Alice Constance Mensah, Ebenezer Okyere, Osei Antwi, Prince Kumi, Joseph Dadzie, Martin Owusu Amoamah. Assessing Foreign Exchange Risk Associated to a Public Debt Portfolio in Ghana Using the Value at Risk Technique. International Journal of Economics, Finance and Management Sciences. Vol. 2, No. 2, 2014, pp. 159-163. doi: 10.11648/j.jefm.20140202.17

\begin{abstract}
VaR is a potential loss. The VaR methodology gives the definition to risk-based capital, or economic capital and confidence level reflects the risk appetite of the bank. This work is a delta-normal VaR application in the case of the Ghanaian economy. It assesses the exchange risk associated to the Ghana public debt portfolio. We used daily spot exchange rates of the Ghana cedi against the three main currencies, the dollar, the euro and the pound. We are interested in the period from $04 / 01 / 2000$ to $31 / 12 / 2009$. We demonstrated that the VaR result is very high and that there is a need for the government to also trade in a currency that can serve as a potential hedge against risk.
\end{abstract}

Keywords: Value- at- Risk, Public Debt Portfolio, Volatility

\section{Introduction}

The globalization of business generates foreign currency risks. This process is irreversible and critical to the survival of most countries. Managing foreign exchange risk is a fundamental component in the safe and sound management of all institutions that have exposures in foreign currencies. It involves prudently managing foreign currency positions in order to control, within set parameters, the impact of changes in exchange rates on the financial position of the institution. The frequency and direction of rate changes, the extent of the foreign currency exposure and the ability of counterparts to honour their obligations to the institution are significant factors in foreign exchange risk management.

Improving debt management has been a Government policy goal in recent years, especially since the country became eligible to the Heavily Indebted Poor Countries (HIPC) and Multilateral Debt Relief Initiatives (MDRI). Furthermore, as Ghana moves towards middle income status, the importance of good debt management will increase as the proportion of concessional aid in external finance declines and Ghana becomes more reliant on non concessional borrowing to meet its external financing needs.
Risk measures how volatile an asset's returns are. By volatility we mean how much the price of an asset fluctuates. The more volatile the asset, the greater is the potential to make large profits or large losses. Given the substantial losses that major banks and corporations have suffered, risk departments are becoming more prominent. In the rouse of several high-profile failures of risk management (for example Barings Bank, Metallgesells chaft, and Orange County), there has been a widespread outcry for an efficient and better quantification of financial risks facing corporate and financial service firms. At the front position of this clamor for a standard risk measure has been Value-atrisk (VaR) as it is well known. To a layman, VaR is often regarded as "mathematical model" dreamed up by rocket scientists-which probably doesn't work anyway. Value at risk (VaR) measures the worst expected loss that an institution can suffer over a given time interval under normal market conditions at a given confidence level. Many governments have tried to adapt the VaR approach to public debt portfolio management requirement. The Danish National Bank, for instance, uses the Cost at Risk $(\mathrm{CaR})$ as an integrated risk managing approach of 
the sovereign debt. This paper is interested in the Ghana public debt management strategy.

We are using the VaR technique within its parametric version to assess the exchange risk associated to the long run public run debt portfolio. Our calculation of VaR is different from the method used by [1]. It is the first study that applies the VaR approach to Ghana economy to the best of our knowledge.

The work answers a very precise question: How much is the maximum potential loss associated with the Ghana long run public debt, due to the three main currencies fluctuations, by a one-day holding period at both 95 th percentile confidence levels?

The VaR result will inform the Government as to which of the currencies have a higher risk and that there is a need for the Government to also trade in a currency that can serve as a potential hedge against risk.

The limitations of the VaR are that it may lead to a wide variety of results under a wide variety of assumptions and methods; it focuses on a single somewhat arbitrary point; it explicitly does not address exposure in extreme market conditions and it is a statistical measure, not a managerial/economic one.

\section{Literature Review}

\subsection{Literature on Value at Risk}

The work on VaR has grown greatly in the last few years. There have been several articles that calculate the estimate of market risk on the basis of VaR using different techniques. For example, [2] compared these methods, and assesses the accuracy of each one. In [3], they examined the likelihood of predicting the variance of risk factors (interest rates, share prices and exchange rates), and then compared parametric and non-parametric methods of measuring VaR. The possibility of predicting all the parameters of distribution of risk factors was examined by [4]. Running back-testing for the VaR model [5], examined the length of time that passed until the first failure of the estimate, as well as performance tests for the failure rate. This test is adopted by the Basle Committee as the basis for examining banks' internal models. Comparison of random foreign exchange portfolios using different VaR models over multiple dates was done [6]. A researcher [7], applied eight different approaches to three hypothetical portfolios and the results showed that the differences among these VaR results (methods) can be very large with VaR estimates varying by a factor of 14 for the same portfolio. VaR criterion as a measure of portfolio's risk on long run horizons was used by [8]. A risk management framework that relies on VaR estimates for complex fixed-income instruments such as mortgage derivatives was outlied [9]. [10,11] initiated theoretical research that relied on the VaR as a risk measurement. [12], also applied the VaR approach based on risk management emerging as the industry standard by choice or by regulation. [13], researched and described VaR -based management by financial as well as non-financial institutions.

The application of VaR techniques is generally restricted to assessing the risks being run in banks treasury or trading operations (for example, securities, foreign exchange and equities trading). It is hardly ever applied to the measurement of the exposure to the interest-rate and foreign-exchange risks that comes from more traditional non-traded banking business (for instance, lending and deposit). Major commercial banks have developed larger scale VaR models to manage their market risks. There are huge varieties of different financial instruments. However, the task of mapping them and estimating their VaR can be very difficult by recognizing that most instruments can be decomposed into small number of more basic, primitive instruments. VaR is a method that summarizes the expected maximum loss (or worst loss) over a target horizon within a given confidence interval. In other words, the VaR models assess the maximum potential loss resulting from an unfavourable fluctuation in price for a given time horizon at a specific confidence level. We can thus define VaR as follows:

For a given time horizon and probability (confidence) level $\alpha(0<\alpha<1) ; V_{a} R_{\alpha}$ represents the expected loss with probability $(1-\alpha)$.

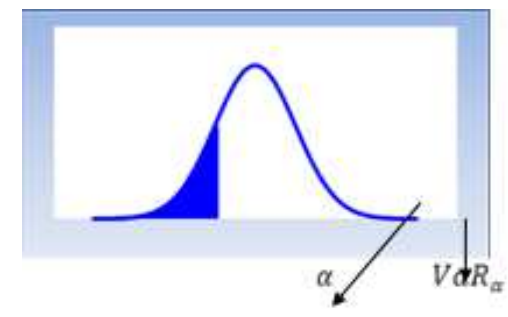

$V a R_{\alpha}$ will be defined for a probability measure $\mathbb{P}$ and some confidence level $\alpha$ as the $\alpha$-quantile of a loss random variable $\mathrm{X}$,

$$
\operatorname{VaR}_{\alpha}=\inf \{x \geq 0 \mid \mathbb{P}[X \leq x] \geq \alpha\}
$$

For a given random variable $X$, the $V a R_{\alpha}$ is based on the $\alpha-q u a n t i l e$ in negative sign, of the distribution function $F_{X}$ :

$$
\operatorname{VaR}_{\alpha}=\inf \left\{-F_{X}^{-1}(\alpha)\right\}
$$

where $F_{X}^{-1}$ is the inverse of the distribution function $F_{X}$.

\section{Methodology}

\subsection{Data and Methodology}

In this study, we applied the standard variancecovariance VaR model to a Ghana representative long run debt portfolio. In this case, the representative portfolio is a close reproduction of the sovereign debt structure. We were interested solely in the exchange rate risk resulting from the three dominating currencies in the debt portfolio: the US dollar, the British pound and European Euro. 


\subsection{Data}

We were interested in the three main currencies composing the Ghana public debt portfolio, namely, the dollar, the euro and the Great Britain pound. In this case, analyzing the exchange risk associated to the Ghana national debt amounts to studying the three flowing exchange rates GHS/USD, GHS/EUR and GHS/GBP. The observation window ranges from 04/01/2000 to $31 / 12 / 2009$ and consists of end-of-the-day quotes. The total observations number was 2608 .

The GHS/USD, GHS/EUR and GHS/GBP, exchange rates were extracted directly from Pacific Exchange Rate Database. The results were analyzed using EViews 5 software.

\subsection{Review of Method}

The returns were calculated as follows: if we denote the closing price (rate) for share $i$ at date $t$ by $r_{i t}$ then the $\log$ return was given as:

$$
R_{i t}=\ln \left(\frac{r_{i t}}{r_{i t-1}}\right)
$$

Though there are other ways of calculating returns, the above is preferred because it allows us to assume that the average periodic return is more close to representing the expected return for the period to come. We continued by constructing the volatility matrix V. We took the standard deviation of the various returns and constructed a volatility matrix by placing the volatilities along the diagonals. Before constructing the standard deviation matrix we multiply each standard deviation by the confidence interval factor. From the normal distribution tables, a 95 percent interval is equivalent to 1.645 standard deviations. We then multiply each of the individual standard deviations by 1.645 to obtain the adjusted volatilities. We use this to calculate our variance covariance matrix VC. The variance covariance matrix is simply the volatility matrix multiplied by the correlation matrix and then we multiply the variance covariance matrix by the volatility matrix to get the variance covariance $\mathrm{VCV}^{\prime}$. Finally, we know that the Ghana long run external debt structure by currency is relatively stable during the studying period. On the other hand, we know also that the Ghana public debt in American dollar represents 50 percent of the total debt portfolio, that in euro is about 20 percent and that expressed in Britain pound is around 20 percent (from Bank of Ghana). The remainder is expressed in other different currencies. We use this as the weighting matrix $\mathrm{W}$ and the VCV matrix to compute the

$$
V a R=\left\{W V C V^{\prime} W^{\prime}\right\}^{1 / 2}
$$

\section{Results and Discussions}

\subsection{Descriptive Statistics}

\begin{tabular}{|c|c|c|c|}
\hline $\begin{array}{l}\text { Series } \\
\text { Frequency } \\
\end{array}$ & $\begin{array}{l}\text { GHS_EUR } \\
\text { Daily data }\end{array}$ & $\begin{array}{l}\text { GHS_GBP } \\
\text { Daily data }\end{array}$ & $\begin{array}{l}\text { GHS_USD } \\
\text { Daily data }\end{array}$ \\
\hline Period & $01 / 04 / 2000 \quad 12 / 31 / 2009$ & $01 / 04 / 2000 \quad 12 / 31 / 2009$ & $01 / 04 / 2000 \quad 12 / 31 / 2009$ \\
\hline $\begin{array}{l}\text { Total Observations number } \\
\text { Statistical Properties }\end{array}$ & 2507 & 2507 & 2507 \\
\hline Mean & 1.110067 & 1.550156 & 0.905653 \\
\hline Median & 1.098700 & 1.619400 & 0.902140 \\
\hline Maximum & 2.164500 & 2.530700 & 1.503400 \\
\hline Minimum & 0.343680 & 0.564630 & 0.344890 \\
\hline Std. Dev & 0.432954 & 0.438544 & 0.230521 \\
\hline Skewness & $0.584880>0$ & $-0.131949<0$ & $0.677223>0$ \\
\hline Kurtosis & $2.949356<3$ & $2.469948<3$ & $4.188557>3$ \\
\hline Jarque-Bera & 143.2024 & 36.62281 & 339.1966 \\
\hline Probability & 0.000000 & 0.000000 & 0.000000 \\
\hline
\end{tabular}

Table 1. Descriptive Statistics.

Table 2. Returns.

\begin{tabular}{llll}
\hline Total Observations number & $\mathbf{2 5 0 6}$ & $\mathbf{2 5 0 6}$ & $\mathbf{2 5 0 6}$ \\
\hline Statistical Properties & & & RGU \\
& RGE & RGP & 0.000568 \\
Mean & 0.000699 & 0.000563 & 0.000178 \\
Median & 0.000522 & 0.000478 & 0.717720 \\
Maximum & 0.712621 & 0.718954 & -0.700380 \\
Minimum & -0.685803 & -0.690996 & 0.025701 \\
Std. Dev. & 0.026234 & 0.026255 & 0.620997 \\
Skewness & 0.809043 & 0.950086 & $479.2900>3$ (leptokurtic) \\
Kurtosis & $417.8979>3$ (leptokurtic) & $430.8078>3$ (leptokurtic) & 23687311 \\
Jarque-Bera & 17974587 & 19110662 & 0.000000 \\
Probability & 0.000000 & 0.000000 & \\
\hline
\end{tabular}

Table 1, gives the descriptive statistics of the three variables. Among the three variables, GHS_GBP has the highest mean value of 1.550 and GHS_USD has the lowest value of 0.9056. GHS_EUR and GHS_GBP exchange rates have platykurtic data sets. That is, flatter peak around their means, which causes thin tails within the distribution. The 
flatness results from the data being less concentrated around its mean, due to large variations within observations. On the other hand, GHS_USD exchange rate has leptokurtic data set. That is the distribution has higher peaks around the mean compared to normal distributions, which leads to thick tails on both sides. These peaks result from the data being highly concentrated around the mean, due to lower variations within observations. In the case of the returns, as shown in table 2, RGE (GHS_EUR returns) has the highest mean value of 0.000699 and RGP (GHS_GBP returns) has a minimum mean value of 0.000568 .

\begin{tabular}{llcl}
\hline \multicolumn{4}{c}{ Volatility (in percentage) } \\
& RGE & RGP & RGU \\
\hline Volatility(Std. Dev) & 2.6234 & 2.6255 & 2.5701 \\
\hline
\end{tabular}

Also, all the returns have leptokurtic distribution. Among the returns, RGP has the highest volatility of $2.6255 \%$, followed by RGE of $2.6234 \%$ and RGU has the lowest volatility of $2.5701 \%$.

Figures $1 \mathrm{~A}, 1 \mathrm{~B}$ and $1 \mathrm{C}$ are histograms of the daily exchange rates for the GHS_EUR, GHS_GBP and GHS_USD.

In all the graphs, the upper and lower tails of each series is greater than that which would be expected if returns were normally distributed. It points to the fact that series of daily returns appears more likely to be samples from some distribution other than normal distribution. Figures 2A, 2B, $2 \mathrm{C}$ and the combined $2 \mathrm{D}$ give an idea about the three exchange rates returns evolutions (See appendix 1). The three variables fluctuate in an interval $[-0.6,0.6]$.

The portfolio calculated VaR is equal to 3.8079 . This result can be interpreted as follows: from 2000 to 2009, at $95 \%$ level confidence, the Ghanaian government could lose at worst, 3.8079 millions of Ghana cedis per day, on a total external long run public debt portfolio evaluated at 100millions Ghana cedis. This loss is exclusively due to the exchange risk associated to the three composing debt portfolio main currencies fluctuations. This single number summarizes the country's exposure to market risk as well as the probability of an adverse move.

\section{Conclusion and Recommendation}

The use of VaR has become one of the means to measuring market risk, for capital requirements and for internal risk management. This first VaR application to assess exchange risk associated to a Ghana's public debt portfolio is valuable. The Ghana exchange rate policy built around the three dominating currencies in the World, the euro, the US dollar and the Great Britain pound, proves itself mainly in the debt portfolio management area. The VaR result is very high and that there is a need for the Government to also trade in a currency that can serve as a potential hedge against risk.

\section{Acknowledgement}

We are most grateful to the Research Department of the Bank of Ghana for helping us with the Data. Also to friends who assisted us in the analysis and the write-up of this study.

\section{Appendix 1}

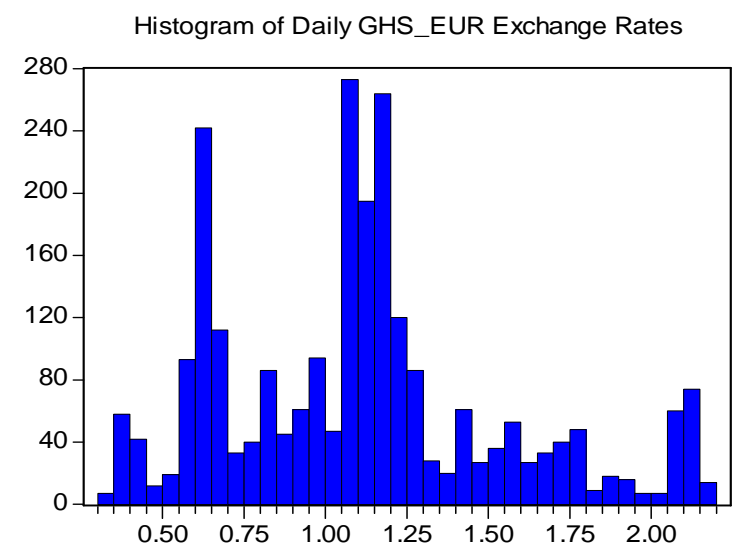

Figure 1A

Histogram of Daily GHS_GBP Exchange Rates

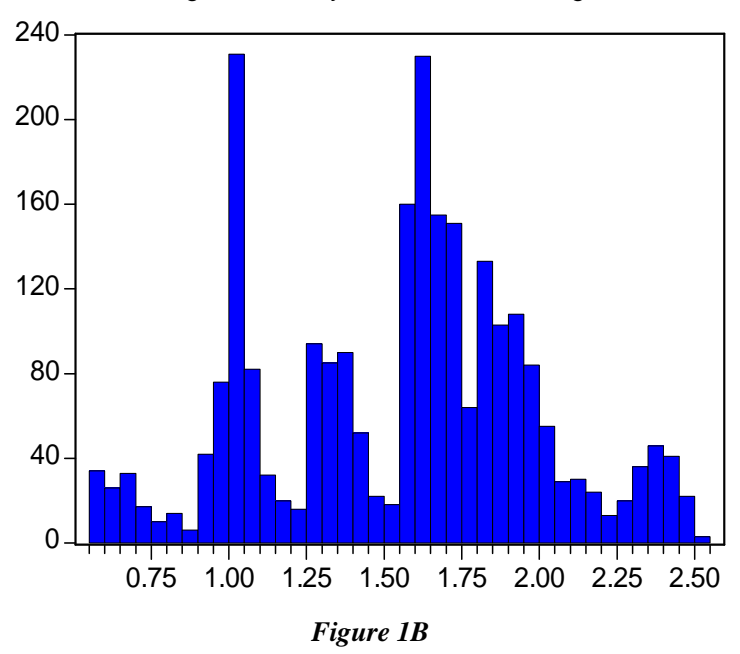

Histogram of Daily GHS_USD Exchange Rates

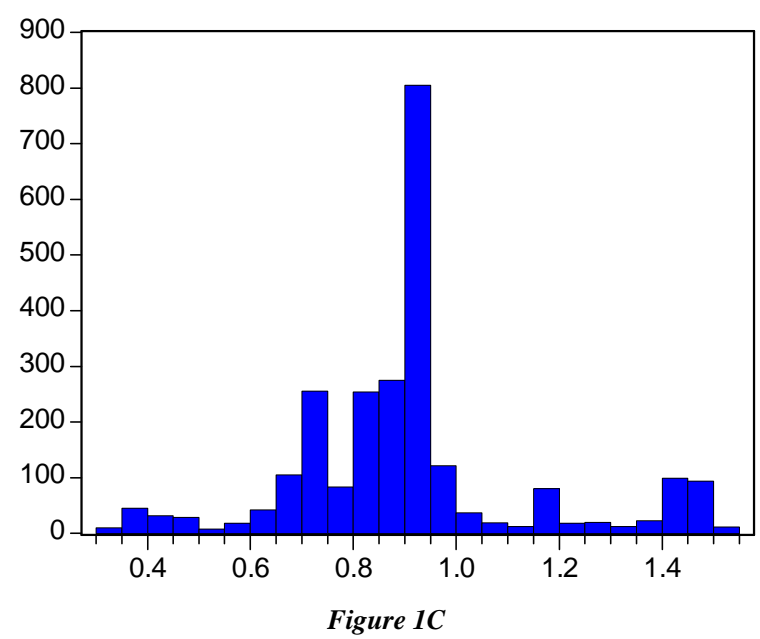


Figure 2A

The GHS_EUR Daily Retums

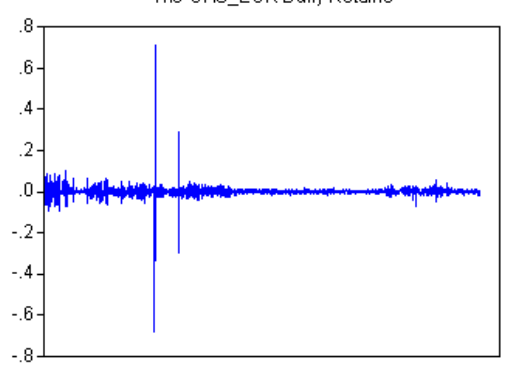

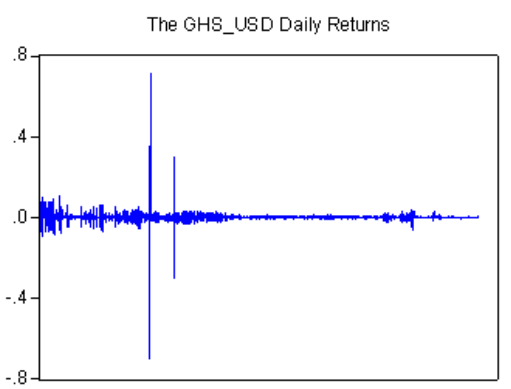

$-\mathrm{RGU}$

Figure 2B

The GHS_GBP Daily Returns
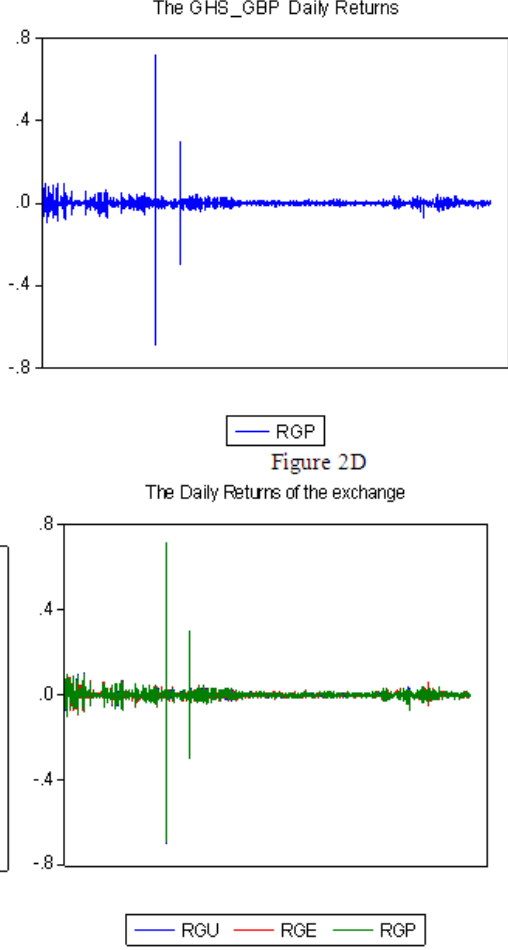

[7] Beder, T. S. (1995). "VaR: Seductive but dangerous." Financial Analysts Journal 1995(Sept-Oct): pp.12-24.

[8] Giannopoulos, K. (2003): VaR modelling on long run horizons: Automation and Remote Control, 64(7), pp. 10941100 .

[9] Singh, M. K. (1997): Value at risk using principal components analysis - For term structure-dependent securities and FX derivatives. Journal of Portfolio Management: 24(1), pp. 101-109

[10] Jorion, P. (1997): Value-at-Risk: The New Benchmark for Controlling Market Risk. Irwin, Chicago, Ill.

[11] Dowd, K. (1998): Beyond Value-at-Risk: The New Science of Risk Management, John Wiley \& Sons, London.

[12] Saunder A. (1999); Credit Risk Measurement: New Approaches to Value-at-Risk and Other Paradigms John Wiley \& Sons, London

[13] Bodnar, G.M., G.S. Hayt and Martson, R.S. (1998): "1998 Wharton Survey of Financial Risk Management by U.S. Non-Financial Firms", Financial Management, Vol. 27, No. 4, pp. 70-91.
[6] Hendricks, D. (1996). "Evaluation of Value at Risk Models using Historical Data." Federal Reserve Bank New York Economic Policy Review 1996(April): 